\title{
La fotografía en los procesos de activación, resignificación y gestión patrimonial: los casos de Exaltación de la Cruz y San Andrés de Giles, municipios de la provincia de Buenos Aires, Argentina
}

\author{
Photography in the processes of activation, resignification and patrimonial \\ management: The cases of Exaltación de la Cruz and San Andrés de Giles, \\ municipalities of the Province of Buenos Aires, Argentina \\ Dra. Cecilia Pérez Winter \\ Investigadora Asistente CONICET - Instituto de Geografía e Instituto de Ciencias Antropológicas, \\ Universidad de Buenos Aires, Argentina \\ cecipw@gmail.com [orcid.org/0000-0002-2880-5834]
}

\section{RESUMEN}

Este artículo indaga el rol, uso e incidencia de la fotografía en el campo patrimonial, con el propósito de tensionar los procesos de activación, gestión y resignificación patrimonial a partir de la técnica e imagen fotográficas en un contexto local, mediante los casos de Exaltación de la Cruz y San Andrés de Giles, municipios de la provincia de Buenos Aires, Argentina. Sostenemos que la fotografía se presenta como un dispositivo incuestionable que así como permite legitimar prácticas y discursos sobre el patrimonio, también posibilita construir resistencias y negociaciones entre los diferentes actores que participan en los procesos de patrimonialización.

PALABRAS CLAVE: patrimonio, gestión cultural, fotografía, ruralidad, provincia de Buenos Aires.

\section{ABSTRACT}

This article looks into the role and significance of photography in heritage field. Its purpose is to discuss activation process, management and resignification of heritage through photographic technic and image, in a local context. We analyze these themes through two cases of study, Exaltación de la Cruz and San Andrés de Giles districts (province of Buenos Aires, Argentina). We argue that the photographic technique and image becomes an unquestionable heritage device that, as well as they allow legitimizing practices and discourses about heritage; they also favored the construction of resistances and negotiations between different actors 
that participate in heritage processes.

KEY WORDS: Heritage, cultural management, photography, countryside, province of Buenos Aires.

\section{INTRODUCCIÓN}

Desde el surgimiento de la fotografía, se han ampliado sus usos, funciones (artísticas, jurídicas, históricas, científica) y propósitos, legitimándose como objeto y práctica sociocultural (Edwards \& Hart, 2004; Bauret, 2010). En ese contexto, podemos incluir el rol de la fotografía dentro del campo patrimonial.

En primer lugar, la fotografía fue propicia para el registro y catalogación tanto de colecciones de obras artísticas como de sitios arqueológicos. En el primer caso, podemos mencionar los trabajos dirigidos por el fotógrafo francés Adolphe Braun (1812-1877), quien formaba técnicos para relevar aquellas piezas encontradas en museos, como el Louvre de París o las pinturas de la Capilla Sixtina en Roma (Freund, 1983, pp. 89-90). Mientras que para el segundo caso, la fotografía contribuyó en llevar adelante muestreos de sitios arqueológicos -algunos de ellos declarados actualmente como "Patrimonio de la Humanidad"-, como el coordinado por el fotógrafo francés Claude-Joseph Désiré Charnay (1828-1915) en México entre 1857-1861 (Ryan, 2013, p. 37). Actualmente, la fotografía -mediante los avances tecnológicos como la fotogrametría-, continúa siendo una de las herramientas ampliamente utilizadas en el registro patrimonial (Toz \& Durán, 2004).

En segundo lugar, las imágenes fotográficas cumplen una función relevante en los procesos de restauración de inmuebles significativos. Ellas son tomadas como documentos confiables a la hora de planear la intervención (Boyer, 2006). Asimismo, las imágenes fotográficas también participan en los procesos de reconocimiento formal del potencial patrimonio -entendiendo por esto su protección legal-, por parte de organismos locales, nacionales o internacionales como la Organización de las Naciones Unidas para la Educación, la Ciencia y la Cultura/UNESCO (UNESCO, 2014).

En tercer lugar, la fotografía -como técnica y objeto- permite registrar y analizar prácticas socio-culturales entre etnógrafos y antropólogos (Edwards, 1992).

Por último, las colecciones fotográficas -y los elementos asociados a su producción- han sido objeto de valorización patrimonial, expresándose la necesidad de su preservación. Desde la UNESCO se ha considerado tempranamente -implícita o explícitamente- a las imágenes fotográficas (y los negativos) como parte del concepto de patrimonio cultural (material mueble). Existen diversos documentos formulados por dicha institución que promueven su accesibilidad y protección a partir de sus valores históricos, culturales, educativos, artísticos, científicos (Carta de Beirut, 1948; Carta de La Haya, 1954; Carta de París, 1964, 1978, 2015a y b). De hecho, la interpretación de algunos documentos formulados por la UNESCO habilita la 
posibilidad de reconocer a la técnica fotográfica y la fotografía como expresiones culturales que contribuyen a fomentar el respeto por la diversidad cultural (Carta de Belgrado, 1980; Carta de París, 2005).

De esta forma, la técnica y la imagen fotográfica -como instrumento y documento- son de gran utilidad cuando se trata de orientar proyectos de gestión y activación patrimonial. Entendiendo la primera como el corpus de regulaciones, instituciones (públicas y privadas) y acciones que regulan, protegen y hacen accesible el patrimonio. Mientras que la segunda, podría ser cualquier forma de jerarquizar, exponer, valorizar e interpretar aquellos lugares, prácticas y objetos significativos que pueden estar o no formalmente declarados como patrimonio.

La técnica y la imagen fotográfica han permitido y facilitado varias tareas que forman parte del proceso de reconocimiento -formal o no- y preservación del patrimonio. Sin embargo, su utilización trae consigo algunos cuestionamientos sobre los procesos de construcción de la imagen que en el ámbito de los estudios fotográficos y visuales han sido ampliamente discutidos (Fontcuberta, 1997; Burke, 2005; Freund, 2011; Dubois, 2015). Así, se entiende que la fotografía como técnica permite crear determinadas imágenes que son generadas en un tiempo/espacio específico. A su vez, que el carácter mimético de una foto -y su capacidad de índex como señala Dubois (2015)- no significa que ella sea objetiva o que muestre la "realidad". La fotografía puede ser espejo y espejismo al mismo tiempo. Es decir, colocarse como constatación científica pero también como una "fabulación poética" (Fontcuberta, 1997, p. 40). Por lo tanto, nos preguntamos: ¿quién/es establece/n, y cómo se construye la legitimación de una fotografía para ser implementada como documento válido para orientar prácticas patrimoniales?, ¿qué otras función/es cumple la fotografía -como técnica e imagen- en los procesos de activación y gestión patrimonial?, ¿qué recaudos habría que considerar a la hora de utilizar la fotografía -como técnica y documento- en los procesos de patrimonialización?, ¿cuándo -y de qué manera- una fotografía o conjunto de fotografías son posibles de patrimonialización?

Ante lo expuesto, el objetivo de este trabajo es explorar y abrir la discusión sobre el rol, uso e incidencia de la fotografía en el campo patrimonial, con el propósito de tensionar los procesos de activación, gestión y resignificación patrimonial a partir de la técnica e imagen fotográficas. Para ello, discutiremos estos temas mediante los casos de Exaltación de la Cruz y San Andrés de Giles, municipios localizados en la provincia de Buenos Aires, Argentina.

Las informaciones presentadas en este artículo fueron construidas a partir del trabajo de campo efectuado en los municipios de Exaltación de la Cruz y San Andrés de Giles en el periodo 2012-2018 en el marco de las investigaciones doctoral (2012-2015) y posdoctoral (2016-2018) de la autora. En ellos se realizaron: entrevistas semi-estructuradas a residentes y funcionarios públicos locales del área cultura, patrimonio y turismo; observación con y sin participación en eventos como fiestas patronales y otras actividades culturales-patrimoniales y turísticas; registro fotográfico y consulta de publicaciones -escritas y visuales- locales y normativas en archivos municipales y de la Ciudad Autónoma de Buenos Aires. 
En el siguiente apartado presentamos el rol de la fotografía en la gestión y activación patrimonial, a partir de los casos de Exaltación de la Cruz y San Andrés de Giles. Luego, discutimos la relación patrimonio-fotografía. Por último, exponemos algunas reflexiones finales.

\section{LA FOTOGRAFÍA EN LA GESTIÓN PATRIMONIAL DE EXALTACIÓN DE LA CRUZ}

El partido de Exaltación de la Cruz se localiza hacia el norte de la provincia de Buenos Aires (Argentina), a unos 80 km de la Ciudad Autónoma de Buenos Aires (Fig. 1). Limita con los municipios de Luján, San Andrés de Giles, San Antonio de Areco, Zárate, Campana y Pilar. Cuenta con 29.805 habitantes, de los cuales 9.244 residen en la ciudad cabecera, Capilla del Señor (INDEC, 2010). El municipio también está compuesto por otras ciudades y parajes como Los Cardales, Parada Robles, entre otros.

En la década de 1990 se llevó adelante la patrimonialización formal del centro histórico de Capilla del Señor. Ello se logró debido al involucramiento de funcionarios de la Comisión Nacional de Monumentos, de Lugares y de Bienes Históricos (CNMLBH), el Instituto Internacional de Medio Ambiente y Desarrollo de América Latina (IIED-AL), la Dirección de Cultura de la Municipalidad de Exaltación de la Cruz y de algunos sectores de la comunidad local de la ciudad mediante talleres participativos. Así, en 1994 el centro histórico de Capilla del Señor fue declarado "Bien de Interés Histórico Nacional” (Decreto Nacional 1648/1994). Cabe señalar, que en dicho proceso de reconocimiento se creó la Asociación Civil Pro-Memoria como una entidad local sin fines de lucro que promovía la activación patrimonial, colaborando con el municipio. Ella estaba compuesta por vecinos y funcionarios de la ciudad (Pérez Winter, 2019b).

A partir de la declaratoria nacional, el municipio impulsó una serie de acciones y medidas de preservación, como la creación de la Comisión de Preservación Patrimonial -dependiente de la Dirección de Cultura- con el fin de mantener la fisonomía del área patrimonializada e idearios asociados a la urbanidad, la educación, la cultura y el progreso. Asimismo, los aspectos históricos y materiales que le valieron la declaratoria nacional fueron activados turísticamente, configurando a la ciudad como el destino turístico del municipio (Pérez Winter, 2019b).

El relato de la declaratoria otorgada por la CNMLBH, coloca a Capilla del Señor como un pueblo pionero en el ámbito de la campaña bonaerense debido a sus adelantos y actividades culturales. Aunque no se detalle específicamente en la declaratoria, varios de los funcionarios del área de Cultura y Turismo del municipio y ex-miembros de la Asociación Civil Pro-Memoria, coinciden en destacar a la fotografía como una de esas innovaciones que caracterizó a la ciudad como un centro cultural entre mediados y fines del siglo XIX:

“... el preceptor Manuel Cruz [...] puso un taller de fotografía. Entonces a partir de ahí ya podés darte cuenta que culturalmente Capilla del Señor era muy fuerte (Exmiembro de Pro-Memoria, 2011). 


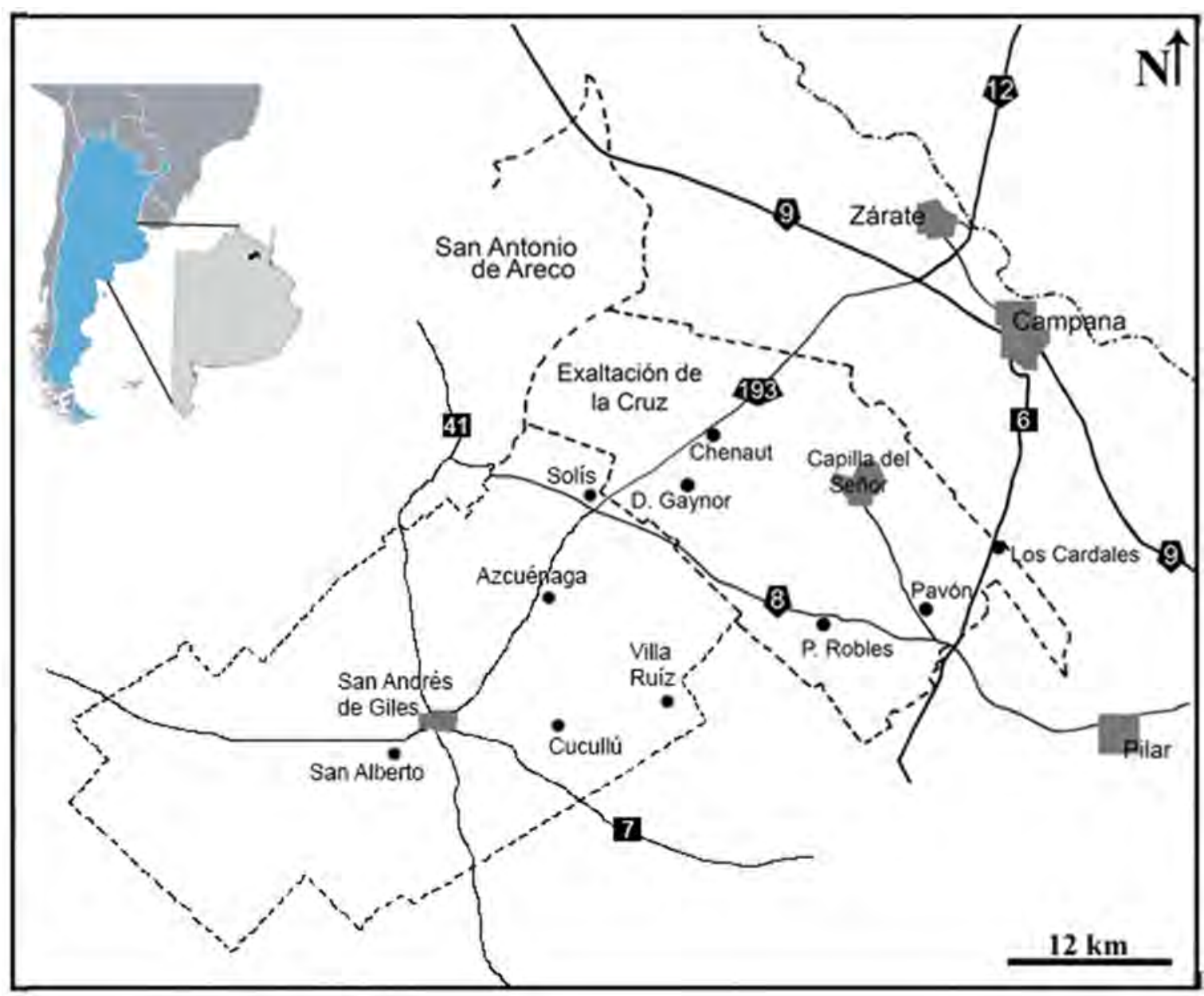

Fig. 1. Localización geográfica de los municipios de Exaltación de la Cruz y San Andrés de Giles (provincia de Buenos Aires, Argentina). Fuente: Elaboración propia.

Manuel Cruz es considerado por varios residentes de Capilla del Señor como un "prohombre" de Exaltación de la Cruz. Varios de los aportes que le valen dicho reconocimiento los llevó adelante entre las décadas de 1860-70. Él no sólo tuvo un taller y dio clases de fotografía en la Biblioteca del pueblo, sino que además, introdujo la primera imprenta con la que editó uno de los primeros periódicos de la campaña bonaerense, El Monitor de la Campaña (Pérez Winter, 2019b). Sin embargo, la relación entre la fotografía y la gestión patrimonial comenzó a tener relevancia luego de la declaratoria de "Bien de Interés Histórico Nacional".

Nuestra investigación, realizada entre los años 2011-2015, nos permitió indagar en los procesos de patrimonialización llevados a cabo en el municipio de Exaltación de la Cruz. Así, se pudo constatar que las políticas patrimoniales se focalizaban en el centro histórico de la ciudad de Capilla del Señor, el área declarada como "Bien de Interés Histórico Nacional", hasta recientemente (Pérez Winter, 2017a, 2018). En este marco, nos interesa discutir el rol de la técnica y la imagen fotográfica en la gestión y activación patrimonial de Exaltación de la Cruz. 
La fotografía como documento para orientar la restauración patrimonial

La declaratoria de "Bien de Interés Histórico Nacional" del centro histórico de Capilla del Señor implica que el estado municipal tiene la responsabilidad de mantener determinadas características (en su estado "original") que hacen a su fisonomía. Para lograr ese objetivo se creó la Comisión de Preservación Patrimonial (CPP) integrada por dos arquitectas y una museóloga, aunque su conformación puede haber variado levemente desde 1994 hasta hoy. La función de la CPP es orientar las intervenciones urbanas de Capilla del Señor -especialmente las que se plantean dentro del centro histórico-, proveer asesoramiento a los residentes que deseen modificar sus casas y/o comercios y formular normativas que permitan proteger el área patrimonial. Las mismas se encuentran en el Código de Ordenamiento Territorial que regula cuestiones como: qué elementos estilísticos y arquitectónicos son permitidos (conservación de la fachada, uso de paleta de colores, alturas máximas, cartelería, iluminación, etc.), qué tipo de intervenciones pueden ser habilitadas; además de incentivos y sanciones.

En los primeros años de actuación, la CPP conformó un catálogo de edificaciones significativas -dentro del área patrimonial- (Ordenanza 56/1999), declarando algunas de ellas de "Interés Municipal". Es decir, fueron formalmente reconocidas como patrimonio local. En su mayoría, corresponden a construcciones erigidas entre los siglos XIX y XX -mismo periodo que fue considerado en la declaratoria nacional- a las que se les atribuye un "valor histórico" y "arquitectónico" (Ordenanzas 88/2002, 11/2004, 39/2010).

En cuanto a los incentivos, algunas normativas buscan fomentar la participación de los residentes en la protección del patrimonio. Entre ellos, el concurso anual "Capilla del Señor, Primer Pueblo Histórico Nacional” (Ordenanzas No 005/1995 y 035/2004), que premia con cinco años de exención del pago de la tasa de Alumbrado Barrido y Limpieza a aquellos vecinos que preserven las fachadas de sus casas, comercios e instituciones, siguiendo los lineamientos de la CPP. En la fiesta patronal del partido, el 14 de septiembre que se celebra en Capilla del Señor, el inmueble ganador es anunciado y recibe una placa de reconocimiento. En 2015 también se propuso eximir entre un 50\% y 100\% de la Tasa de Derecho de Construcción a aquellos que edifiquen sus propiedades siguiendo los estilos arquitectónicos "tradicionales" (Ordenanza 032/2015).

La CPP, además, impulsa la recuperación de espacios públicos. En este sentido se puede mencionar, entre otros ejemplos, la remodelación del Paseo del Arco Iris (que se encuentra en la entrada de la ciudad) en 1996, donde se suelen realizar ferias y actividades recreativas; la reparación de la Iglesia, ubicada frente a la plaza principal -que también fue restauradaen el año 2000; la intervención del Camping municipal El Veredón, donde se celebran eventos como la Expo Rural. Y en 2010, coincidiendo con los festejos del Bicentenario de la Revolución de Mayo (1810) en Argentina, se restauró la Casa Cosmopolita. Originariamente el inmueble había sido un Centro de Mutuo Socorro (1884) de las comunidades inmigrantes (italianos, españoles), que durante el 2000 -plena crisis económica nacional- había quedado 
abandonado. Cabe señalar que en Exaltación de la Cruz, como en otros partidos de la provincia de Buenos Aires, hubo y existe población afrodescendiente pero su proceso de instalación en el área tuvo características socio-económicas diferentes a las que se constituyeron para los inmigrantes recién señalados (Pérez Winter, 2015). Hoy el Centro se utiliza como Centro Cultural, Sala de Exposiciones y Teatro.

A su vez, la CPP apoya las iniciativas de intervención de privados que preserven o recuperen la "autenticidad" de las propiedades, sobre todo de aquellas que son consideradas patrimoniales. La autenticidad patrimonial como cualidad a ser conservada, es entendida en términos absolutos -sinónimo de original y no réplica- y objetiva. Es decir, que debe haber una investigación que dé cuenta de la veracidad de los aspectos físicos y la significatividad de los valores que condensa (Pérez Winter, 2019b).

A pesar del trabajo de asesoramiento y concientización sobre el patrimonio local -y nacionalizado-, las intervenciones orientadas por la CPP en el centro histórico de Capilla del Señor no se desarrollan armónicamente. Las tensiones emergen entre la CPP y vecinos por diversas razones. Entre ellas, porque los lineamientos que la CPP intenta establecer en ocasiones se contraponen con las necesidades/deseos que los residentes del área patrimonial poseen respecto al uso y estilización de sus propiedades. En otros casos, porque difieren en identificar cuál es el "momento original" del inmueble y qué elementos utilizar para recuperar su "autenticidad". Por ejemplo, entre el 2013-2014 se restauró una antigua casona ubicada en una esquina concurrida frente a la plaza principal de la ciudad (Fig. 2). Según los relatos de varios vecinos, la casona había sido una antigua botica durante la primera mitad del siglo XX (Fig. 2A). Luego, su fachada fue modificada y se convirtió en un negocio (Fig. 2B). Recientemente fue intervenida, manteniendo su función dentro del rubro comercial (Fig. 2C). El frente que se observa en la figura 2B se mantuvo así por al menos dos décadas, suficiente tiempo como para que algunos residentes la hayan considerado su fachada "original".

Esta esquina de acá, la esquina rosada que le llamaban. Que hubo toda una discusión. Porque cuando esta gente [dueños actuales] la fue a hacer se cuestionaba que la habían modificado. Es que la esquina ya estaba modificada. Tenía como unos arcos que nunca existieron, entonces conseguimos la foto antigua y las aberturas eran como ésta, eran rectas. Recuperó lo que era la fachada original (Miembro de la CPP, 2013).

Fuimos [dos amigas residentes de la ciudad] a almorzar a ese restaurant que está frente a la plaza. Cuando estábamos comiendo me dice 'yo te quiero hacer una pregunta, dice, '¿qué te parece lo que están haciendo con la casa de la esquina? [...], te pregunto a vos que como vos siempre has estado con Pro-Memoria', [...]..., 'le pongo un 20 no un 10'. Me dice 'claro, no, porque había una ventana de medio punto así para la otra calle'. 'No', le digo, 'eso fue lo que una persona modificó para hacer otro negocio. Ahora esta gente está 
tratando de volverlo lo más parecido a lo que fue primitivamente'. Y yo te puedo hablar tranquilamente de setenta y cinco años atrás porque tengo buena memoria. [...]. Y bueno, las arquitectas [de la CPP] han entrado a preguntar y nosotros en Pro-Memoria tenemos fotos guardadas (Ex-miembro de Pro-Memoria, residente del centro histórico de Capilla del Señor, 2012).

La última intervención de la antigua casona fue orientada por la CPP y avalada por una ex-miembro de la Asociación Pro-Memoria, quien detenta un saber experto por su actuación en el campo patrimonial, su memoria y la posesión de una fotografía que muestra un "momento original" de cómo se veía la propiedad señalada. No obstante, otros residentes, que también se posicionan como especialistas en el campo patrimonial, cuestionan algunos lineamientos de restauración por parte de la CPP, utilizando también la fotografía como documento legitimador de su propuesta.

Cuando yo encontré esta casa [Fig. 3], existía todavía un archivo [...] bastante completo con la ficha de cada casa y la fotografía más antigua que se había conseguido. Entonces, en base a esa foto yo pude restaurar cómo era esta casa. [...]. Gracias a la fotografía que yo encontré, por ejemplo, le devolví los balaustres que tenía esta casa. En fin, traté de llevarla al mayor parecido que tenía en lo que se verificó [...]. ... estas señoras de la supervisión [de la CPP] me dijeron que le pusiera rejas a los balaustres porque estaban pensados para rejas. Sí, tienen razón. Y seguramente hubiese quedado más linda la casa con rejas, pero resulta que no las tenía (Restaurador de arte, residente del centro histórico de Capilla del Señor, 2013).

Como se observa en los fragmentos de testimonios presentados, a pesar de las experticias de cada entrevistado/da, la CPP es la "voz autorizada". Entendiendo por esto a aquella/s persona/s habilitada/s, que se reconoce/n y es/son reconocida/s dentro de un grupo al cual pertenece/n y/o representa/n (Goodenough, 1965) -en parte por el capital simbólico acumulado-, para producir un tipo de discurso asociado al patrimonio. A su vez, porque en términos de Bourdieu (1972), posee/n una eficacia performativa, detentando un cierto poder para exponer discursos que generen consenso con otros actores. Esta figura que se posiciona como la "voz autorizada", junto con el apoyo de otros sectores, son los que suelen guiar el proceso de patrimonialización -que deviene en protección legal o no- bajo ciertos términos e intereses. Si bien la "voz autorizada" de la CPP logra construir consensos con ciertos sectores que residen en el centro histórico de la ciudad, en otros casos, ella es cuestionada por otros que también buscan posicionarse como expertos en el tema.

Lo interesante de estos procesos de restauración es que las posturas contrapuestas entre la CPP y el restaurador de arte, recuerdan ciertos lineamientos establecidos por el crítico de artes inglés John Ruskin (1819-1900) y por el arquitecto francés Eugéne Viollet-le-duc (1814-1879). El 
primero impulsaba el mantenimiento de los bienes. Mientras que el segundo promovía medidas de restauración que permitieran que las edificaciones vuelvan a un estado "ideal" de su estilo arquitectónico, más que a su estado "original” (Choay, 2001). Tanto para el caso de la casona comercial (Fig. 2), como para la casa residencial (Fig. 3), la fotografía se presentó como recurso y documento confiable, verosímil para disputar saberes y campos de acción patrimonial.

Es a partir de la imagen fotográfica que, por una parte, se pone en tensión qué lineamientos de restauración son válidos. Por otra parte, se determina cuál es el "momento originario" o "la perpetuación" -en términos de Dubois (2015, p. 177)- del inmueble, para orientar las intervenciones que resguarden su "autenticidad" patrimonial. De esta forma, una imagen fotográfica determinada puede convertirse en un "holotipo fotográfico" del -en este caso- inmueble patrimonial. Es decir, que una imagen fotográfica -de tantas que pueden existir- es seleccionada por una "voz experta" para configurarse como el documento de referencia para orientar futuras prácticas, como las de restauración/conservación o para
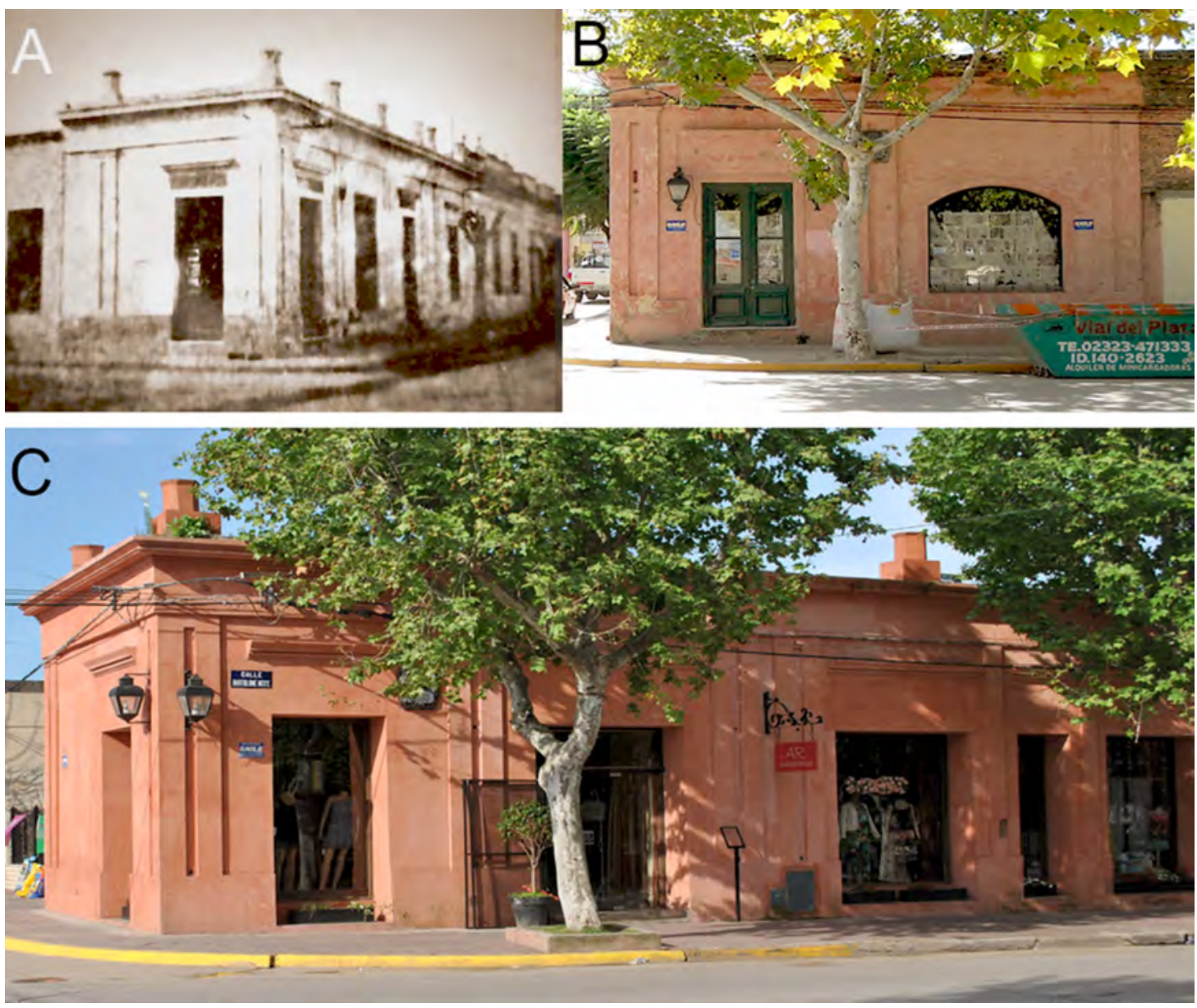

Fig. 2. Casona antigua, centro histórico de Capilla del Señor. A. "Foto antigua" que muestra el local de la botica (primera mitad del siglo XX). B. Inmueble modificado (2010). C. Restauración actual (2014). Fuente:

Fig. A, Archivo Fotográfico de la Municipalidad de Exaltación de la Cruz; Fig. B y C, C. Pérez Winter. 
promover otro tipo de prácticas y representaciones. Por lo tanto, es interesante indagar qué elementos entran en juego para construir la legitimidad de esa imagen fotográfica como documento referencial, independientemente de los usos y fines que de ella se hagan, como el permitir visualizar la "autenticidad” o "estado original”. Así, otras características podrían estar incidiendo en la construcción de legitimación de un "holotipo fotográfico" para un elemento patrimonial determinado. Una de ellas podría ser el estado de preservación de la propia foto, el autor -si se conoce-, su procedencia (si es de una colección, archivo, etc.), aspectos estéticos, la temporalidad y hasta el punctum -en términos de Barthes (2006)-, es decir, lo que genera en quienes se colocan como las "voces autorizadas" sobre el patrimonio. Todos esos elementos también permiten otorgarle veracidad a la imagen fotográfica.

De todas formas, lo que no está ocurriendo en las situaciones señaladas anteriormente con los testimonios de entrevista, es el cuestionar la verosimilitud de cualquier fotografía como documento. La capacidad mimética de la imagen fotográfica para representar fragmentos de una versión de realidad -mediante un aparato que parecería otorgarle cierta objetividad-, le valió a la imagen fotográfica el conformarse como un documento veraz (Bauret, 2010; Burke, 2005; Dubois, 2015; Freund, 1983) y hasta científico, al aplicarse protocolos sobre cómo realizar los registros que son avalados por determinadas instituciones (Tagg, 1988; Wilder, 2009). Las fotografías construyen una relación singular de lo que representan.

Estas cualidades de objetividad y verosimilitud que se le adjudican a la técnica y su producto fotográfico han sido puestas en cuestión en el ámbito de los estudios visuales. Arguyendo en algunos casos que la fotografía es "pura invención” (Fontcuberta, 1997, p. 167). No obstante, desde el campo patrimonial, la foto se presenta como una copia fiel de realidad por exponer una relación de contigüidad entre la imagen y su referente (Dubois, 2015, p. 54). En este caso, en cómo la foto capta una imagen de un inmueble adquiriendo un poder de designación, al señalar a esa edificación particular en un momento determinado (Dubois, 2015).

Por lo tanto, a partir de la búsqueda y selección de una fotografía como testimonio -que debe ser relativamente antigua y evidenciar una cierta esteticidad del elemento patrimonial que se busca intervenir-, se le asigna y certifica historicidad y genuinidad al patrimonio, validando su anclaje espacio-temporal. Y ello permite legitimar -no sin tensiones- posicionamientos sobre la conformación de lo que podríamos denominar la "perpetuación de la autenticidad fotográfica" de un inmueble al establecer cierta imagen como su "holotipo fotográfico" del elemento en cuestión. No obstante, la construcción de una imagen fotográfica no deja de ser subjetiva y muchos menos las lecturas e interpretaciones que a partir de ella se desprenden. Tal vez en unas décadas -si se carece de otros registros visuales-, la figura 3 sirva para visualizar la nueva "perpetuación de autenticidad fotográfica" de la casa mencionada al reconocer esa imagen como su nuevo "holotipo fotográfico". 


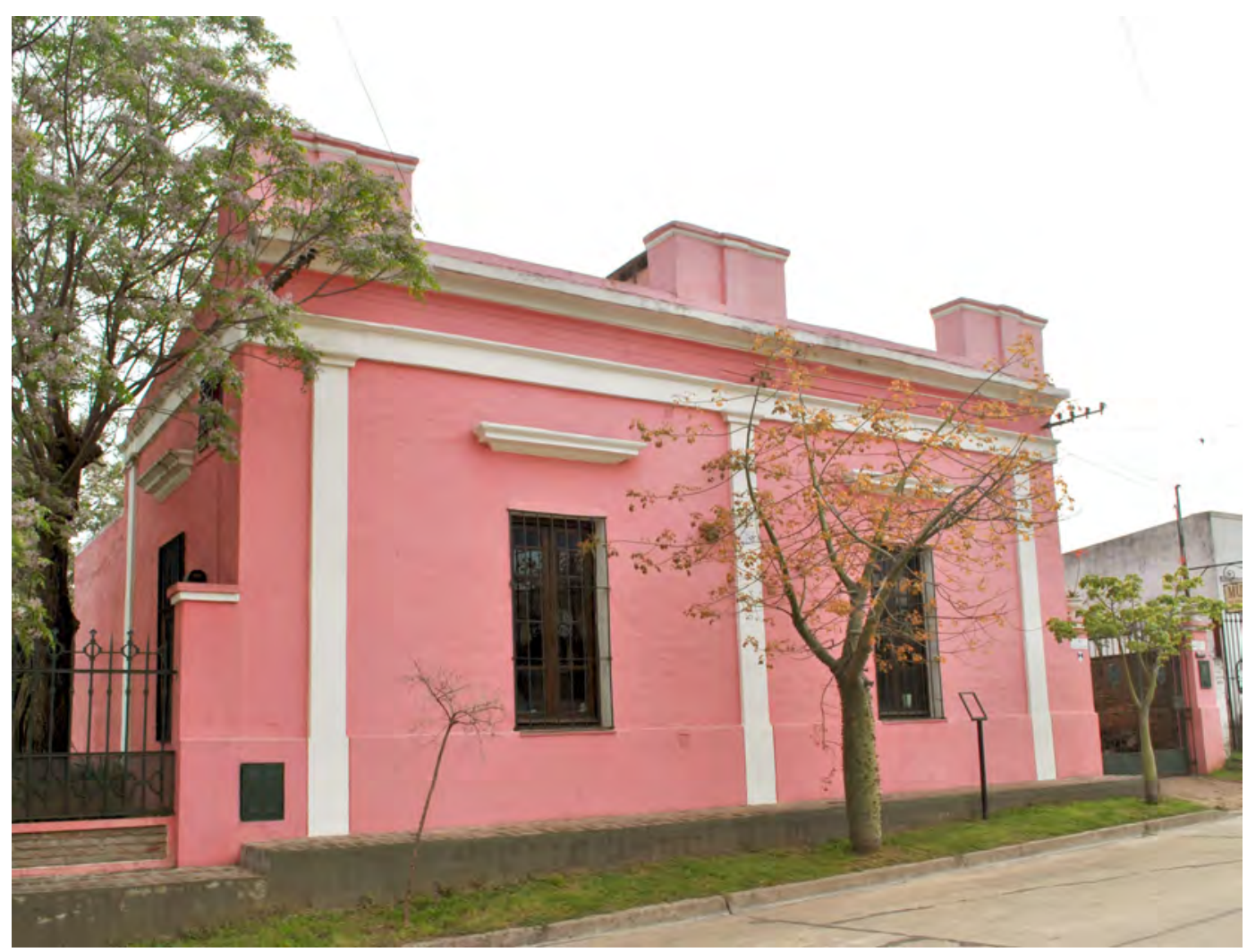

Fig. 3. Casa antigua restaurada, centro histórico de Capilla del Señor (2014). Fuente: C. Pérez Winter.

\section{La fotografía como estrategia de "concientización" patrimonial}

Durante el proceso de patrimonialización nacional que llevó a declarar al centro histórico de Capilla del Señor como "Bien de Interés Histórico Nacional", varios entrevistados residentes de la ciudad -que participaron de los talleres propuestos por la CNMLBH y el IIEDAL-, argumentaron que para ellos fue como "descubrir" la significancia de ciertos elementos representativos de su historia y cultura locales, los cuales merecían ser preservados.

[...] ellos hicieron todo [miembros de la CNMLBH y el IIED-AL], hicieron ver y bueno uno un poco descubría en qué consistía eso. Porque era tan abstracto "pueblo de interés histórico" pero claro, te hacían ver un montón de cosas [...]. Vos después te vas dando cuenta de que esas cosas trascienden (Funcionario área cultura, residente de Capilla del Señor, 2013).

Durante la década de 1990, la acción de los expertos de la CNMLBH y el IIED-AL incidió en la mirada local sobre cómo ver con nuevos ojos un lugar que para los residentes de Capilla del Señor era cotidiano y carente de singularidad. Casi 20 años después del reconocimiento 
nacional, la Dirección de Cultura comenzó a implementar estrategias de gestión participativa con el interés de consolidar una identidad "exaltacrucense" unificada que evitara las concepciones localistas que existían en el interior del municipio (Pérez Winter, 2019b). Así, se organizó una serie de actividades para activar y legitimar una versión de identitad local. Entre ellas podemos mencionar: (i) el concurso para presentar propuestas de diseño de la bandera del distrito (Ordenanza 60/2000); (ii) la configuración del evento musical anual Exaltación Canta, en el que se presentan bandas y cantantes de diferentes grupos etarios y se anuncia el ganador en la fiesta patronal del partido; (iii) la extensión de las políticas patrimoniales hacia el interior del distrito; (iv) la constitución de un Observatorio del Paisaje en el año 2013; (v) la promoción turística de todo el partido y no sólo de Capilla del Señor como el único destino, entre otras (Pérez Winter, 2017a, 2018, 2019a). En este marco, se llevó adelante la organización, desde la Dirección de Cultura, de concursos fotográficos orientados a jóvenes -entre 11 y 18 añosresidentes en el distrito (Fig. 4).

En la página oficial del municipio se anunciaba que el concurso:

[...] buscará acercar a los participantes con su entorno natural y social, a partir de una experiencia sensorial que les permitirá retratar rasgos del patrimonio arquitectónico, cultural y natural de Exaltación de la Cruz. La finalidad del trabajo será poner de manifiesto, en una serie de reproducciones fotográficas, ejemplos claros de nuestro bagaje histórico-geográfico (http://www.exaltaciondelacruz.gov.ar/index.php?option=com_content\&view=article\&id=4 235\%3Aconcurso-de-fotografia-qcultura-patrimonio-y-ambiente\&catid=93\%3Aactividadespromociones-eventos-\&Itemid=28).

El concurso permitiría "acercar" el patrimonio local y otros elementos potenciales a su comunidad, exponiendo además ciertas innovaciones respecto a cómo se concebía el patrimonio local -y nacionalizado- dentro del ámbito de la gestión de la Dirección de Cultura. En primer lugar, no se focaliza sólo en lo histórico-cultural, como ocurría hasta recientemente (Pérez Winter, 2017a; 2018), sino que se abre hacia la valorización de lo "natural”. En segundo lugar, se deja de destacar la materialidad del patrimonio, al procurar "una experiencia sensorial" que la fotografía parecería poder captar a través de la cámara (Sontag, 2016), mediante el "acto fotográfico". Éste implica, como sostiene Dubois (2015, p. 36), un acto de recepción y contemplación. En tercer lugar, expone una perspectiva más integradora del patrimonio, al insinuar que las imágenes fotográficas permiten testimoniar el “bagaje histórico-geográfico” que el distrito posee. Así, el patrimonio es un elemento, práctica, construcción que tiene su correlato espacial que la fotografía posibilita relevar gracias a sus características de designación (Dubois, 2015). Nuevamente aparece la idea de que la captura de una imagen a partir de la fotografía, consolida un anclaje espacio-temporal del patrimonio, haciéndolo propio. En cuarto lugar, la fotografía se coloca como un mecanismo de registro y 

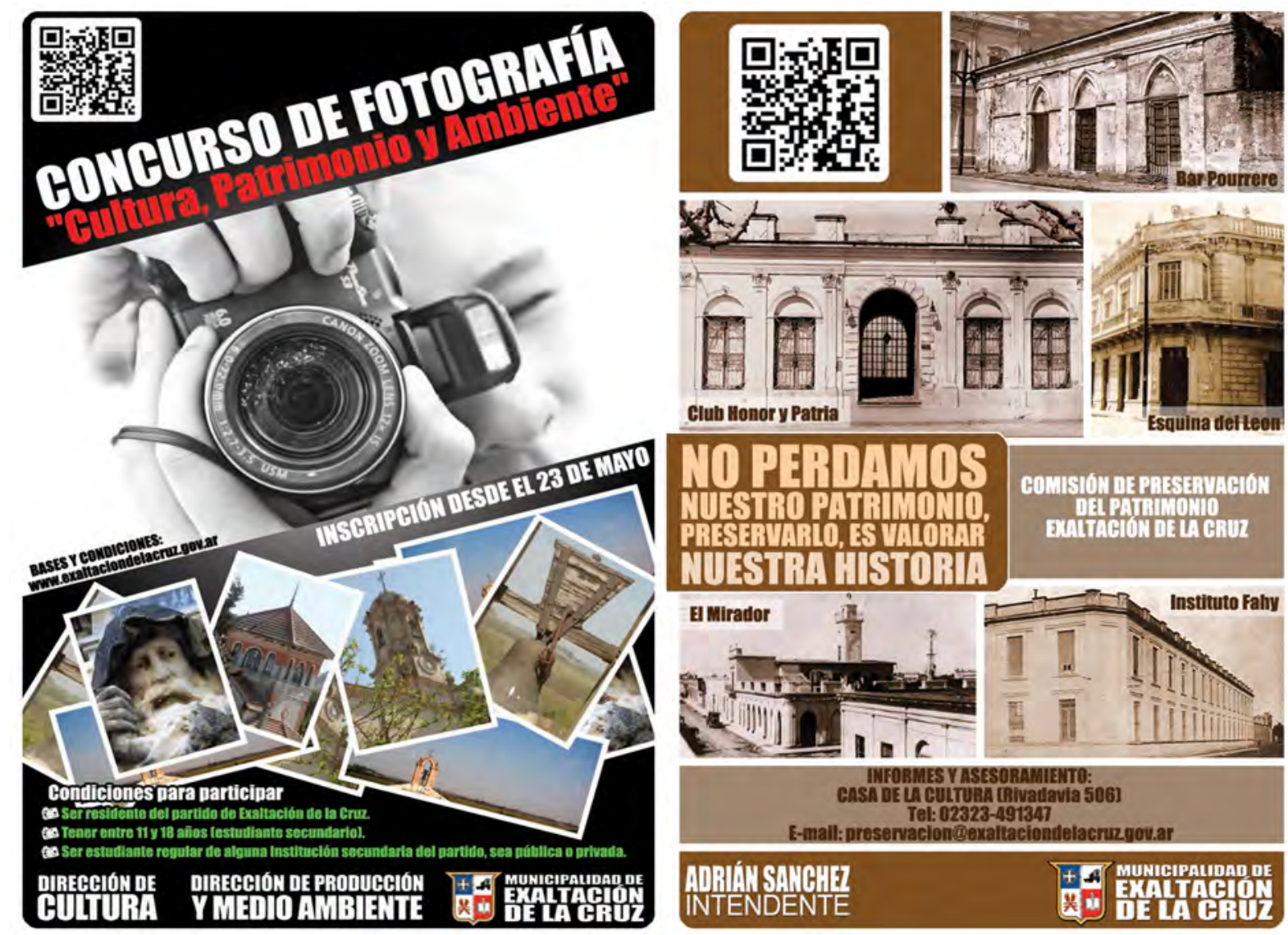

Fig. 4. Banners de promoción del $2^{\circ}$ concurso fotográfico "Cultura, Patrimonio y Ambiente" (2012). Fuente: Dirección de Cultura de Exaltación de la Cruz.

como instrumento que posibilita explorar, registrar y descubrir (Bauret, 2010; Ryan, 2013). En este caso, la técnica fotográfica permite reproducir el proceso exploración/descubrimiento al convertir lo cotidiano en extraño para volverlo a ver con otra mirada. Ya que la cámara capta de una manera distinta lo que se nos presenta a nuestros ojos y la fotografía nos permite percibir un "inconsciente óptico" al que no podríamos acceder de otra manera (Benjamín, 2014). En quinto lugar, promueve la participación de las comunidades locales al proponerles actuar como fotógrafos/as. Consecuentemente, la técnica fotográfica se coloca como un posible instrumento de activación patrimonial. En este marco, la fotografía aparece como un dispositivo que genera nueva "evidencia" (Fontcuberta, 1997) de los -potenciales- patrimonios locales, legitimando su existencia. Por lo tanto, y complementando los planteos de Prats (2004), la naturalización de la idea del patrimonio puede ocurrir por medios visuales, no sólo discursivos. A su vez, la mirada local, mediada por el aparato fotográfico, se materializa en la foto exponiendo diversos aspectos (estéticos, espacio-temporales) que para quien realiza la toma configuran al elemento patrimonial. Como advierte Fontcuberta (1997), aunque se haya instalado la idea de que a partir de la fotografía los "objetos se delinean ellos mismos", 
hace falta un operador. Justamente, porque el fotógrafo -y no el aparato- es quien elige en qué momento sacar la foto, el tipo de encuadre, el dispositivo a utilizar, entre otros. Por último, y como señala Susan Sontag, las fotografías nos enseñan un nuevo código visual que: "alteran y amplían nuestras nociones de lo que merece la pena mirar y de lo que tenemos derecho a observar" (Sontag, 2016, p. 13). Así, la fotografía se legitima como una estrategia de activación y apropiación patrimonial relevante.

\section{La fotografía como objeto patrimonial}

La declaratoria otorgada por la CNMLBH al centro histórico de Capilla del Señor legitimó una versión de la historia local y los valores sarmientinos ya mencionados (educación, cultura, progreso). Algunas de las informaciones que allí se señalan ya habían sido difundidas décadas antes por los diarios locales, con suplementos especiales y en las escuelas. Posteriormente, la Dirección de Cultura realizó una serie de acciones para intentar establecer y consolidar una conexión entre ese pasado "brillante cultural" de antaño señalado en la declaratoria -segunda mitad del siglo XIX-, y el presente (Pérez Winter, 2019b).

Sin embargo, recientemente la Dirección de Cultura comenzó a valorizar otros periodos, hechos y personajes, configurando otras versiones de la historia local. Ello fue acompañado de una serie de aperturas dentro del campo patrimonial que no habían ocurrido anteriormente (Pérez Winter, 2019a). Estas aperturas ya habían sido concebidas por la CNMLBH, entre las décadas de 1980-90, con el retorno de la democracia en el país (Pagano, 2012; Rotman, 2012; Pérez Winter, 2017b).

Así, en la década del 2000, la Dirección de Cultura creó el Archivo de Historia Oral y el Archivo Histórico Municipal (Ordenanza 59/2000) con el fin de obtener testimonios de pobladores del distrito que relaten eventos ocurridos durante el siglo XX. Asimismo, en 2014, las Direcciones de Cultura y Turismo, crearon una página en la plataforma Facebook para conformar el Archivo Fotográfico "Nuestro Partido" (Fig. 5). Si desde una perspectiva nostálgica la técnica fotográfica registra un "pasado en extinción” (Sontag, 2016, p. 62) y el apego hacia un lugar que está por desaparecer (Fontcuberta, 1997), cuando ese ya no existe, la imagen fotográfica que lo perpetúa se torna patrimonialmente valiosa. Por lo tanto, la conformación de un archivo -físico o virtual- se presenta como una alternativa para protegerlo y difundirlo.

El propósito del Archivo Fotográfico "Nuestro Partido" es constituir un "testimonio visual" de "la" historia del distrito. El archivo disponible en Facebook está compuesto de 24 fotografías que muestran instituciones significativas como el hospital municipal, la iglesia, clubes y hoteles de Capilla del Señor. Se exponen fotos con gente que residió en el distrito realizando alguna actividad o evento (https://es-la.facebook.com/pages/category/Community/ Archivo-Fotogr\%C3\%A1fico-de-Nuestro-Partido-246060418928750/). Asimismo, existen otras que se encuentran resguardadas en la Dirección de Cultura, ya que las personas interesadas en 

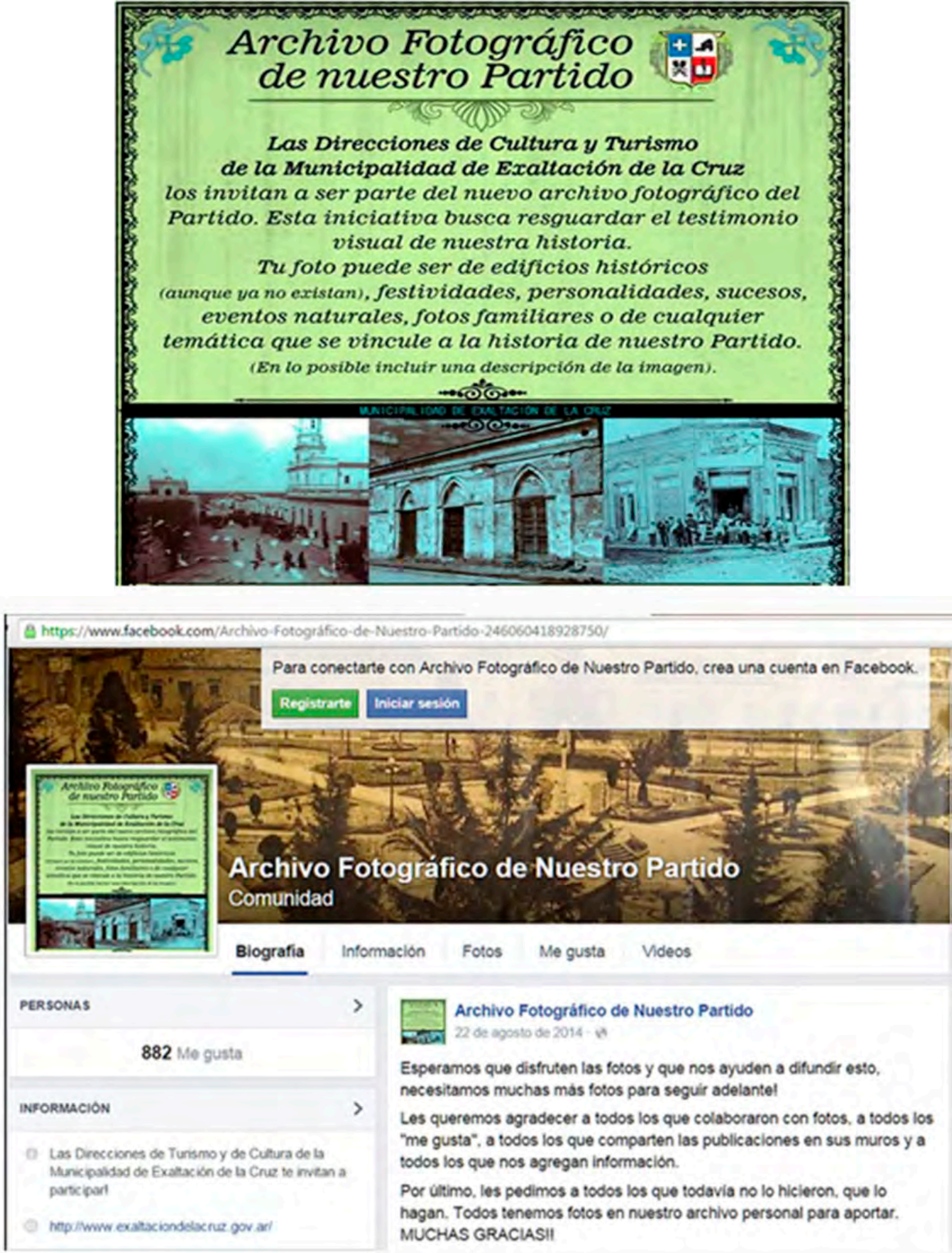

Fig. 5. Banner y página Facebook del archivo "Nuestro Partido" de Exaltación de la Cruz. Fuente: Dirección de Cultural de Exaltación de la Cruz (2014). 
participar con el archivo pueden acercarse y dejar las fotos para digitalizar. Actualmente, existen otras propuestas no oficiales de blogs que difunden imágenes fotográficas del municipio como la página "Memorias de Capilla” configurada en 2013 (http://memoriasdecapilla.blogspot. com/p/fotos-del-ayer.html). Algunas de las imágenes allí presentes también se encuentran disponibles para descargar en el archivo del Facebook de la municipalidad.

En este caso, Facebook se presenta como una forma de socialización que posibilita construir nuevas estrategias participativas para conformar archivos públicos. Así, los habitantes del distrito, o cualquiera que se considere exaltacrucense y que resida en otro lugar, puede involucrarse, no sólo donando, sino proveyendo información sobre las imágenes allí expuestas. Esta propuesta posibilita construir colectivamente otras versiones de la historia hegemónica de la ciudad -y el partido- legitimadas en la declaratoria nacional. Asimismo, este tipo de archivos permite ampliar, actualizar y consolidar una "comunidad imaginada" (Anderson, 1993) "exaltacrucense”, que se resignifica a sí misma mediante la interacción que esta plataforma habilita entre quienes forman parte de esa "comunidad-archivo". Ello se produce con el "compartir" y disponibilizar imágenes fotográficas que son acompañadas de relatos y recuerdos que esta nueva "comunidad” aporta. Así, se otorgan sentidos a esas fotografías y se construye colectivamente otras lecturas, representaciones, acercamientos y vínculos entre el pasado más reciente (siglo XX) y el presente. Ya lo afirmaba Baudelier que la fotografía permite conservar una "huella" del pasado y se presenta como un instrumento de una memoria documental de "lo real" (citado en Dubois, 2015, p. 49). Asimismo, el estar, el identificarse y el comentar recuerdos sobre una fotografía, significa inscribirse en una memoria colectiva determinada, contrariamente a lo que planteaba Fontcuberta $(1997$, p. 31) para el caso de Tasunke Witco. Las fotografías posibilitan construir una “crónica-retrato”, no sólo de las familias (Sontag, 2016, p. 18), sino de las comunidades. Y el archivo fotográfico de Exaltación de la Cruz estaría favoreciendo el explorar y exponer otras historias del partido, más allá de aquella legitimada por la declaratoria nacional. Por otra parte, en este marco en el que se concibe la fotografía como documento, ellas actúan como disparadores de memoria y como representaciones -y/u "holotipos fotográficos"- de aquellos elementos que no perduraron -aunque se mantienen en el recuerdo- y que desde el presente se los resignifica como patrimonios locales.

\section{LA FOTOGRAFÍA DESDE LA MIRADA LOCAL EN SAN ANDRÉS DE GILES}

El partido de San Andrés de Giles se ubica hacia el norte de la provincia de Buenos Aires (Fig. 1), a unos 105 km -aproximadamente- de la Ciudad Autónoma de Buenos Aires. Cuenta con 23.027 habitantes (INDEC, 2010). Está compuesto por su ciudad cabecera homónima y varios pueblos y parajes, en su mayoría conformados a partir de la extensión (entre fines del siglo XIX y principios del XX) de las vías ferroviarias que atraviesan el municipio. Entre ellos nos interesa mencionar: Azcuénaga, Villa Ruiz, Cucullú, siendo un total de 15 asentamientos. 
El distrito es de fácil acceso, mediante la ruta nacional 7 y la provincial 41. Linda con los municipios de Exaltación de la Cruz, San Antonio de Areco, Suipacha, Luján, Mercedes y Carmen de Areco.

En San Andrés de Giles las primeras declaratorias patrimoniales a nivel local son de -al menos- la década de 1980 (Ordenanza 73/1988, 199/88). Bajo la categoría patrimonial de "Lugar Significativo" se reconocieron espacios productivos, como la estancia la Merced (Ordenanza 49/1988); y otros lugares de sociabilidad y cotidianeidad característicos de los ámbitos rurales bonaerenses, como el almacén de ramos generales "la casa Terrén", ubicado en Azcuénaga (Decreto Municipal 154; Ordenanza 20/1993); o el "boliche de Tejo", localizado en Cucullú (Decreto Municipal 747/2001; Ordenanza 688/2001).

Si bien el municipio cuenta con algunas normativas y una comisión encargada de la preservación patrimonial (Ordenanza 1245/2007, Decreto Municipal 940/2012), desde la Oficina de Turismo -creada en el año 2000- se promueven las mayores activaciones patrimoniales. En particular, se destacan aquellos lugares (ej. pueblos y parajes) y prácticas (ej. celebraciones locales) vinculados a la ruralidad del partido (Pérez Winter, 2019a), independientemente que la CNMLBH ha declarado -recientemente- como "Sepulcro Histórico Nacional" (Decreto Nacional 633/2017) a la sepultura que resguarda los restos del pintor argentino Enrique de Larrañaga (1900-1956) en el cementerio norte de San Andrés de Giles.

Asimismo, las áreas de Cultura y Turismo del municipio suelen organizar, como en Exaltación de la Cruz, concursos y muestras fotográficas con imágenes que exponen diferentes lugares del partido. Sin embargo, en el marco del desarrollo turístico del distrito orientado desde las políticas municipales, se conformó una iniciativa no municipal que interesa exponer a continuación.

\section{La fotografía como pertenencia}

A comienzos de la década del 2000, la Argentina atravesaba una etapa de crisis socioeconómica que había impactado significativamente en los ámbitos rurales, producto de la implementación de políticas neoliberales que llevaron a una reestructuración del campo (Teubal, 2006; Craviotti 2007). En este contexto, el turismo -inicialmente impulsado desde el sector privado con la apertura de las estancias al visitante y con programas estatales de diversos organismos públicos (ej. Instituto Nacional de Tecnología Agropecuaria, Secretaría de Agroindustria, Secretaría de Turismo) orientados a pequeños productores- se presentó como una estrategia de revitalización de esos ámbitos (Román \& Ciccolella, 2009).

El municipio de San Andrés de Giles, con colaboración de un promotor, comenzó a promover el turismo en los pueblos y parajes rurales del partido -aquellos con menos de 2.000 habitantes-. Algunos de ellos lograron incorporarse a programas nacionales y provinciales de turismo rural que buscan poner en valor el patrimonio local, adquiriendo mayor promoción y visibilidad (Pérez Winter, 2018, 2019a). Entre los visitantes que fueron acercándose a estas 
propuestas se encontraba un experimentado fotógrafo argentino, Diego Arranz, quien ya organizaba safaris fotográficos en diversos lugares del país y el exterior. A su vez, él ya formaba parte de Fotoescape, un emprendimiento cultural y fotográfico que, entre sus objetivos:

[...] brindan ayuda a pueblos en vías de desaparición y con entidades oficiales con el fin de desarrollar productos culturales, siendo agentes de diálogo en relación a la difusión de cada lugar evitando la invasión de grandes multitudes a pueblos pequeños con la pérdida de identidad que ello genera (http://www.fotoescape.com.ar/ QuienesSomos/QuienesSomos.php).

El interés del fotógrafo por contribuir en la revitalización de los pueblos rurales lo llevó a organizar el proyecto "Ojos de Campo, taller de fotografía para chicos de pueblos rurales" en el año 2005 (http://www.ojosdecampo.com.ar/). Así recuerda un miembro del proyecto el proceso de gestación del taller:

[...] un día un fotógrafo Diego Arranz, era por el 2002, llegó a hacer turismo. A recorrer y conoció Azcuénaga, [...] y le digo ‘vamos a Cucullú’ [...]. .... armamos con la gente del pueblo la visita guiada [....]. Después de conocerlo bien a Diego le propongo un día, desde la fotografía, como los chicos del campo no están contaminados, cómo desde la lente pueden ver lo que otros no ven, vos descubrís en ellos lo que otros no ven. [...]. Costó muchísimo [...]. Y hoy los chicos, si te metés en la página ‘Ojos de Campo’ son nuestros embajadores (Promotor turístico, residente de San Andrés de Giles, 2017).

El propósito del taller es promover una actividad artística a los participantes, generar una alternativa laboral y fortalecer el sentido de pertenencia (http://www.ojosdecampo. com.ar/OjosDeCampo/Acerca-del-Taller.html). Y como se menciona en el fragmento de entrevista, el proyecto también busca recuperar la mirada "no contaminada" de quienes participan, contraponiéndose -tácitamente- con la mirada urbana turística-mercantilizadora y externa. Por otra parte, se sostiene que los chicos y chicas del taller -de entre 6 y 14 años, al ser residentes de esos ámbitos rurales, pueden ver "lo que otros no ven". Por lo tanto, la fotografía -utilizada y generada por ellos- permitiría hacer visible lo que para otros es invisible, valorizando y reconociendo la subjetividad de quienes producen las fotos. Aquí vuelve a aparecer la idea de "descubrimiento" que se señaló para el caso de Exaltación de la Cruz con los concursos fotográficos. La diferencia es que aquí se construye un "nosotros" -los adultos no locales- quienes van a descubrir esos lugares gracias a las producciones fotográficas que esos/as chicos/as realizan desde el taller.

En la página del proyecto "Ojos de Campo" se puede visualizar la producción fotográfica realizada por las chicas y los chicos de los diversos pueblos de San Andrés de Giles como: Tuyutí, Cucullú, Espora, Villa Ruiz, Solís. Muchas de ellas muestran retratos y 
auto-retratos, paisajes de un campo tecnificado y otras actividades productivas allí realizadas como la manufactura artesanal de ladrillos, además de personajes y detalles que exponen contrastes en el interior de sus lugares de residencia. Las fotos son a color, blanco y negro y otras intervenidas. En ellas se refleja el sentido lúdico pero también estético que el taller propone. Por lo tanto, se va construyendo colectivamente, entre el fotógrafo que dirige, sus colaboradores y quienes asisten como participantes al taller, un código visual sobre cómo volver a mirar lo cotidiano, lo rural. En este caso, la fotografía como técnica e imagen se presentan como mediadoras en la construcción de sentidos de pertenencia y de apropiación del lugar a partir del "acto fotográfico".

\section{LA FOTOGRAFÍA COMO OBJETO Y DISPOSITIVO PATRIMONIAL}

En este artículo hemos presentado una serie de casos que nos permitieron indagar en el rol de la fotografía como técnica y como imagen dentro del campo patrimonial. Ellos nos posibilitaron desnaturalizar y poner en discusión el vínculo y el uso de ambos en los procesos de gestión y activación patrimonial. En primer lugar, señalamos que la imagen fotográfica no tiene significación en sí misma: su sentido le es exterior, está esencialmente determinado por su relación efectiva -y afectiva- con su objeto y su situación de enunciación. El sentido se lo otorgan aquellos que la utilizan y disputan (Dubois, 2015), como el certificar la autenticidad de ciertos inmuebles patrimoniales, el tensionar saberes y experticias, el otorgarle singularidad al individualizar algo como único o el construir memorias colectivas.

En segundo lugar, dentro del campo patrimonial se tensionan diferentes posturas epistemológicas de la imagen fotográfica: como un "espejo de lo real", debido a su cualidad mimética y verosimilitud y como "huella de un real", en el cual la fotografía es inseparable de su experiencia referencial (Dubois, 2015, pp. 73-74). En este sentido, propusimos que se pueden configurar y legitimar "holotipos fotográficos" de un objeto/inmueble patrimonial.

En tercer lugar, hemos expuesto y analizado cómo la imagen fotográfica se constituye como un documento incuestionable dentro del campo patrimonial. Al contrario de lo que ocurre en el ámbito de los estudios visuales, en el cual la fotografía se coloca como fuente de sospecha, de indagación y no como corroboradora de una verdad (Fontcuberta, 1997). Por ello, es preciso tomar ciertos recaudos en el marco de su implementación. Autores como Didí Huberman (2008), Rose (2002) -entre muchos otros- nos acercan algunas recomendaciones al respecto. Entre ellas, conocer y analizar cómo se construyeron esas imágenes fotográficas, en qué contexto, quién fue el autor, qué -y cómo- es lo que se está mostrando y qué quedó fuera del encuadre, analizar sus temporalidades -la de la toma y la de su lectura en el presente- entre otras cuestiones.

En cuarto lugar, hemos examinado la participación del aparato fotográfico -acompañado de la técnica y su producto- en los procesos de selección, jerarquización, documentación, singularización, certificación patrimonial. Por lo tanto, entendiendo que el patrimonio y los procesos de patrimonialización son dinámicos, son campos de disputa en los que se 
negocian, resisten, reivindican demandas, derechos, versiones identitarias y diferentes intereses sociales, políticos, culturales y económicos; y ante lo expuesto y analizado en este artículo, proponemos identificar a la técnica y la imagen fotográfica como dispositivos -en el sentido foucaultiano (García Fanlo, 2011)- patrimoniales. Es decir, como elementos que, junto a los discursos, normativas e instituciones patrimoniales, legitiman y/o refuerzan la construcción y difusión de ciertos idearios, narrativas y concepciones sobre el patrimonio.

Por otra parte, también hemos planteado cómo la fotografía -tanto el aparato como la imagen- puede devenir en patrimonio. A pesar de los cuestionamientos que se formulan en torno a concebir a la fotografía como un documento, existen ciertas características -además de su capacidad de index, el punctum o su aparente verosimilitud- que nos permiten entender el valor que se le atribuye para constituirse como un potencial patrimonio. En este sentido, nos interesa recuperar algunas ideas planteadas por Candau y Mazzucchi Ferreira (2015). Estos autores proponen indagar en la affordance de ciertos elementos, sosteniendo que es esa característica la que impulsa la patrimonialización. Asimismo, señalan que cada objeto tiene una posibilidad de acción por su materialidad que le atribuye una función; la cual depende de la interacción que el objeto mantiene con un cierto organismo que posee su particular sistema sensorio-motor para percibirlo. La affordance de un elemento puede ser múltiple y esta plasticidad es la que ellos sostienen se puede encontrar en los patrimonios. De esta forma, plantean que a ciertas herencias del pasado les corresponde una affordance patrimonial que se encuentra contenida en un elemento determinado. Esa conexión es lo que promueve que ciertos elementos -materiales o inmateriales- terminen siendo reconocidos como patrimonios mientras que otros no. En el caso de la fotografía, ella permite fijar imágenes de fragmentos de pasados -que no deja de ser un acto arbitrario y selectivo (Dubois, 2015)-, produciendo un objeto que presenta lo visible e intocable, junto con el ahora y el entonces (Sontag, 2016) y que puede acumular diversos y contrastantes sentidos y funciones, es decir, su affordance. Y ello, es una de las razones por las cuales una imagen fotográfica puede devenir en un objeto patrimonial, mediante un proceso de descontextualización, recontextualización y resignificación (Kopytoff, 1986).

Por otra parte, la fotografía también se presenta como un dispositivo patrimonial, en el sentido que permite indagar y configurar memorias colectivas, promover nuevas formas participativas de identificar, construir y empoderarse de aquellos elementos que consideramos significativos, como así también, posibilita difundir y acercar los “patrimonios” hacia diferentes ámbitos y sectores de la sociedad.

\section{CONCLUSIONES}

Las fotografías -realizadas por cámaras analógicas o digitales- son imágenes y objetos que existen en un espacio y tiempo irrepetible y que además perpetúan en ellas mismas un espacio-tiempo que permite acercar distancias entre lo representado y quien lo observa. 
Ellas son producidas en un contexto por diversos motivos, adquiriendo significaciones y resignificaciones por quienes las contemplan (Edwards \& Hart, 2004; Benjamín, 2014; Dubois, 2015). A su vez, las fotografías pueden adquirir agencia, impulsar a quien las observa a preguntar, cuestionar, actuar de alguna manera motivada por una imagen que siente que lo interpela. Por eso la fotografía es producto de un pasado pero también de un presente (Edwards, 2001). Asimismo, las fotografías están conectadas con ciertos paisajes, objetos, lugares, y conectan versiones de pasado con presentes, haciendo visible lo invisible hasta lo que no aparece en el encuadre de la fotografía (Didí-Huberman, 2008). Por ello, y otras características mencionadas a lo largo de este artículo, ellas han sido tan útiles y necesarias en el campo patrimonial.

A modo de perspectivas a futuro, nos interesa continuar indagando algunas temáticas como: profundizar en el uso de la fotografía como constructora de memorias, la configuración y otras formas de utilizar potenciales "holotipos fotográficos 1 ", dar cuenta de aspectos vinculados a la fotografía "como pecado" (Fontcuberta, 1997) en el ámbito patrimonial. Es decir, cómo se configuran, difunden y comercializan, imágenes fotográficas -y "holotipos fotográficos"- de ciertos "patrimonios" que así como pueden reforzar su sacralización, también pueden promover su banalización.

Por último, la fotografía -como técnica e imagen- adquiere un rol relevante en diferentes aspectos que hacen a los procesos de patrimonialización, en sus consensos y en sus tensiones. Sin embargo, como se expuso en este trabajo, aspectos de la fotografía que han sido ampliamente discutidos en el ámbito de los estudios visuales han sido naturalizados en el campo patrimonial, lo que nos lleva a sostener que es una temática que debe ser replanteada e indagada. Este artículo ha buscado generar un aporte a esa problemática y esperamos continuar desarrollando esta línea de investigación.

\section{REFERENCIAS}

Anderson, B. (1993). Comunidades imaginadas: Reflexiones sobre el origen y la difusión del nacionalismo. Buenos Aires: Fondo Económico de la Cultura.

Barthes, R. (2006). La cámara lúcida. Notas sobre la fotografía. Buenos Aires, Paidós.

Bauret, G. (2010). De la fotografía. Buenos Aires: La Marca.

Benjamín, W. (2014). Breve historia de la fotografía. Madrid: Casimiro.

Bourdieu, P. (1972). The economics of linguistic Exchanges. Social Sciences Information, 16(6), 645.

Boyer, C. (2006). La Mission Heliographique: Architectural photography, collective memory and the patrimony of France, 1851. En J. Schwartz \& J. Ryan (Eds.), Picturing place. Photography and the geographical imagination (pp. 21-54). London: Tauris.

1 Por ejemplo, los "holotipos fotográficos" ¿pueden participar -en términos de Jenkins (2003)- de círculos de representación turísticos? 
Burke, P. (2005). Visto y no visto. El uso de la imagen como documento histórico. Barcelona: AMA.

Candau, J., \& Mazzucchi Ferreira, M. L. (2015). Mémoire et patrimoine: des récits et des affordances du patrimoine. Educar em Revista, 58, 21.

Cartas de UNESCO disponibles en: http://portal.unesco.org/es/ev.php-URL_ID=12024\&URL_ DO=DO_TOPIC\&URL_SECTION=201.html.

Choay, F. (2001). A alegoría do Patrimônio. San Pablo: Unesp.

Craviotti, C. (2007). Agentes extrasectoriales y transformaciones en el agro argentino. Revista de la CEPAL, 92, 163-174.

Didí-Huberman, G. (2008). Images in spite of all. Four photographs from Auschwitz. Chicago: Chicago University Press.

Dubois, P. (2015). El acto fotográfico y otros ensayos. Buenos Aires: La Marca.

Edwards, E. (1992). Anthropology and Photography 1860-1920. Nueva Haven: Yale University Press.

Edwards, E. (2001). Raw histories. Photographs, anthropology and museums. Oxford: Berg.

Edwards, E., \& Hart, J. (2004). Photographs objects histories. On the materiality of images. Nueva York: Routledge.

Fontcuberta, J. (1997). El beso de Judas. Fotografía y Verdad. Barcelona, GG.

Freund G. (1983). La fotografía como documento social. Barcelona: GG.

García Fanlo, L. (2011) ¿Qué es un dispositivo? Foucault, Deleuze, Agamben. A parte Rei, revista de Filosofía, 74, 1-8.

Goodenough, W. (1965). Rethinking "Status" and "Role": Toward a General Model of the Cultural Organization of Social Relationships. En M. Banton (Ed.), The Relevance of Models for Social Anthropology (pp. 1-25). Londres: Tavistock.

INDEC. (2010). Censos de población. Disponibles en: www.indec.mecon.ar

Jenkins, O. (2003). Photography and travel brochures: The circle of representation. Tourism Geographies: An International Journal of Tourism Space, Place and Environment, 5(3), 305-328.

Kopytoff, I. (1986). The cultural biography of things: commoditization as process. En A. Appadurai (Ed.), The social life of things: commodities in cultural perspective (pp. 89122). Nueva York: Cambridge University Press.

Pagano, N. (2012). La cultura histórica argentina en una perspectiva comparada. La gestión de la CNMMyLH durante las décadas de 1940-1990. II Congreso Internacional de Filosofía de la Historia. Dimensiones de la experiencia histórica, 2-19.

Pérez Winter, C. (2015). "Patrimonio” afroargentino de la pampa bonaerense. ¿Un potencial producto turístico? En J. Martínez Peria \& M. Ghidoli (Eds.), Estudios Afrolatinoamericanos 2. Actas de las Cuartas Jornadas del GEALA (pp. 189-201). Buenos Aires: GEALA.

Pérez Winter, C. (2017a). Del turismo "cultural" al "rural”. Un caso de la pampa bonaerense (Argentina). Cuadernos de Geografía. Revista Colombiana de Geografía, 26(2), 261-278. 
Pérez Winter, C. (2017b). La preservación de los centros históricos: rupturas y continuidades en las pautas de valorización de la Comisión Nacional de Museos Monumentos y Lugares Históricos. Revista Andes, 28(8), 1-21.

Pérez Winter, C. (2018). La resignificación patrimonial y turística de los pueblos rurales bonaerenses: Fiestas, gastronomía y participación local. En A. L. Guerrero, M. De Batista \& M. E. Estada (Eds.), XII Bienal del Coloquio Transformaciones Territoriales. Interrogantes y desafíos en las territorialidades emergentes (pp. 1063-1078). Bahía Blanca: bookit!

Pérez Winter, C. (2019a). El "retorno al campo" desde la mirada local. Redescubriendo los atractivos patrimoniales pampeano-bonaerenses (Argentina). Revista Pasos. (En prensa).

Pérez Winter, C. (2019b). Patrimonio y procesos de patrimonialización de dos "pueblos" de la provincia de Buenos Aires (Argentina). Colección Constelaciones. Buenos Aires: Editorial de la Facultad de Filosofía y Letras, Universidad de Buenos Aires.

Prats, L. (2004). Antropología y patrimonio. Barcelona: Ariel.

Román, F., \& Ciccolella, M. (2009). Turismo rural en la Argentina. Concepto, situación y perspectivas. Buenos Aires: Ed. Instituto Interamericano de Cooperación para la Agricultura (IICA).

Rose, G. (2002). Visual Methodologies. An Introduction to the Interpretation of Visual Materials. Londres: Sage.

Rotman, M. (2012). Dinámica de los inicios institucionales del campo patrimonial nacional. Regulaciones legales y primeros lineamientos de un organismo rector de Patrimonio. XXVIII Reunião Brasileira de Antropologia (ABA), 1-16.

Ryan, J. (2013). Photography and Exploration. Londres: Reaktion books.

Sontag, S. (2016). Sobre la fotografía. Buenos Aires: Debolsillo.

Tagg, J. (1988). El peso de la representación. Ensayos sobre fotografías e historias. Barcelona, GG.

Teubal, M. (2006). Expansión del modelo sojero en la Argentina. De la producción de alimentos a los commodities. Realidad Económica, 220, 71-96.

Toz, G., \& Durán, Z. (2004). Documentation and analysis of cultural heritage by photogrametric methods and GIS: a case study. En A. Orhan (Ed.), Actas del XXth ISPRS Congress, Volumen XXXV Part B5 (pp. 438-441). Turquía: ISPRS.

UNESCO. (2014). Elaboración de propuestas de inscripción en la lista del patrimonio mundial. París: ONU.

Wilder, K. (2009). Photography and Science. Londres: Reaktion books. 